\title{
Direito e geografia: o espaço do direito e o mundo da geografia ${ }^{1}$
}

\section{Law and geography: the law's space and the world of the geography}

\author{
MARIO GIUSEPPE LOSANO² \\ Professor emérito de Filosofia do Direito na Universidade do Piemonte Oriental “Amedeo Avogadro" (Itália) \\ Tradução: \\ ALFREDO DE J. FLORES \\ (PPGDir - UFRGS)
}

\begin{abstract}
RESUMO: O direito tende ao isolamento, como é possível ver no positivismo radical de Kelsen ao explicar o direito através do direito, e rejeitar qualquer forma de investigação interdisciplinar. Pelo contrário, o direito precisa interagir com outros campos científicos e, portanto, o presente texto traça um amplo panorama da interação entre direito e geografia. O Direito Público, por exemplo, precisa da geografia a fim de definir tanto as fronteiras externas de um Estado em relação a outros Estados, e as fronteiras internas de regiões, províncias, etc. Direito, geografia e política desempenharam um papel importante durante as ditaduras europeias do século XX: "Geopolítica" não era apenas um objeto de pesquisa cultural, mas também uma justificação relevante da conquista militar do "espaço vital". Na mesma época, em paralelo com a "Geopolítica", uma nova disciplina foi criada - "Geojurisprudência", mas com um sucesso muito menor. Após a Segunda Guerra Mundial, a geopolítica estava de fato abandonada, sendo considerada um ingrediente ideológico das ditaduras e substituída pelo estudo das "relações internacionais": outro nome para quase o mesmo assunto. Hoje, o estigma gerado pela ditadura está superado, e a geopolítica retorna como uma disciplina científica. Um dos motivos desse renascimento se deve ao fato de que a globalização mudou a percepção do espaço também no mundo jurídico. As fronteiras dos Estados não são mais relevantes para as empresas multinacionais, Internet, satélites, ecologia, problemas atômicos ou poluição, etc. A tecnologia espacial transformou o espaço aéreo em um lugar semelhante ao espaço da Terra - com implicações econômicas e militares gigantescas. No campo legal, as empresas multinacionais estão elaborando regras supraestatais - o chamado soft law - com uma forte, embora não estatal, força vinculante. O conflito entre a globalização e o tradicional, geograficamente delimitado Direito Estatal, é uma das causas da atual crise econômica mundial. Por isso, abre-se a discussão sobre a necessidade de se voltar às normas jurídicas originadas e territorialmente vinculadas ao Estado, e também para re-inventar uma limitação do soft law corporativo, apesar de ser gerado pelo Estado por meio do hard law.
\end{abstract}

Palavras-chave: Fronteiras; Geopolítica; Globalização; Direito Público; Soft Law.

ABSTRACT: Law tends to isolation, as can be seen in Kelsen's radical positivism explaining law through law, and rejecting any form of interdisciplinary research. On the contrary, law needs to interact with other scientific fields and therefore the present text traces a broad overview of the interaction between law and geography. Public Law, for instance, needs geography in order to define both the outside borders of a State in comparison with other States, and the internal borders of regions, provinces etc. Law, geography and politics played a seminal role during the European dictatorships of the $20^{\text {th }}$ century: "Geopolitics" was not only a subject of cultural research, but also a relevant justification of the military conquest of "vital space". In the same era, paralleling with "Geopolitics" a new discipline was created - "Geo-jurisprudence", but with a far lesser success. After World-War 2 geopolitics was de facto abandoned, being considered an ideological ingredient of the dictatorships, and substituted by the study of "international relations": another name for almost the same subject. Today the dictatorship-originated stigma is overruled and geopolitics comes back as a scientific discipline. One of the reasons of this renaissance is due to the fact that globalization has changed the space perception also in the legal world. State borders are not any more relevant for multinational enterprises, Internet, satellites, ecology, atomic or pollution problems etc. The space technology transformed the heaven space in a place similar to the earth space - with gigantic economical and military implications. In the legal field, the multinational enterprises are elaborating over-statual rules - the so called "soft law" - with a strong, although non-statual binding force. The conflict between globalization and traditional, geographically delimitated State law is one of the causes of the present economical world crisis. Therefore it opens the discussion on the need of coming back to State originated and territorially vinculated legal norms, also to re-invent a limitation of the corporate "soft law" though a State-generated "hard law".

Keywords: Borders; Geopolitics; Globalization; Public Law; Soft Law. 


\section{PREMISSA}

Trata-se de texto que apresentei no dia 28 de janeiro de 2010 por ocasião de recebimento de título de Doutor honoris causa por parte da Faculdade de Direito da Universidade Carlos III de Madrid. Naquele momento, convidei os presentes a percorrer comigo o itinerário que vincula o direito à geografia, buscando uma resposta ao quesito sobre como adaptar o direito atual, nascido dentro dos limites do Estado nacional oitocentesco, a um mundo sem fronteiras, tecnológico e globalizado. Já as ditaduras europeias falavam de "geojurisprudência"; hoje se fala de "geo-direito" e para o futuro - são anunciados inquietantes cenários: qual seja, a substituição do direito rígido (produto de um Estado democrático) por um direito maleável (soft law, resultante das empresas, que por sua natureza são autocráticas, e das organizações multinacionais, que não são algo melhor). Antecipo a minha conclusão: tenho por necessário o retorno a um direito rígido também para empresas multinacionais; sou favorável a um hard law estatal ou supranacional (mas democrático), e não a um soft law empresarial.

As severas previsões para o futuro, com que se conclui o último parágrafo, foram formuladas no ano de 2009 e, naquele então, poderiam talvez parecer excessivas: infelizmente, o colapso econômico de 2011 demonstra que aquelas considerações eram ditadas não desde um infundado pessimismo, mas desde um sadio realismo.

\section{A BAIXA INTERDISCIPLINARIDADE DO DIREITO}

O direito opera no mundo físico, ou seja, naquilo que os geógrafos chamam de "espaço"; contudo, tende a tomá-lo em consideração o menos possível. O direito, sustentam os juristas, se ocupa somente das relações entre pessoas, como se as pessoas não estivessem com os pés no chão, ou seja, no "espaço".

De fato, o direito não pode esquivar-se de ocupar-se do espaço geográfico, seja no interior do Estado-nação, seja nas relações entre os Estados, seja, hoje, no ainda não delimitado espaço cósmico. $\mathrm{O}$ exemplo talvez mais clássico de amálgama entre direito e espaço seja o Tratado de Tordesilhas de 1494, que dividia entre Espanha e Portugal o mundo em parte então conhecido. Curioso documento sobre as relações entre direito e espaço: uma pessoa que não era o proprietário - o Papa atribuía a dois Estados soberanos o direito de propriedade sobre um bem indeterminado, isto é, sobre terras que eram em parte conhecidas e em parte a descobrir. $\mathrm{O}$ direito, como bem se vê, não tinha em conta a geografia.
No séc. XIX, a formação dos Estados nacionais europeus pode ser lida como uma verdadeira e própria epopeia geográfica; antes: geopolítica. Discutia-se se a Alemanha deveria tornar-se um Estado unitário, segundo um modelo groß-deutsch (ou seja, compreendendo tanto a Prússia como as monarquias danubianas da Áustria e da Baviera) ou klein-deutsch (ou seja, sem a Áustria e sob o comando da Prússia). Nesta discussão, falava-se de religião, de tradições, de economia, mas não de geografia.

$\mathrm{Na}$ Itália, o processo de unificação da península exigia a solução de problemas territoriais e institucionais: monarquia ou república? Estado centralizado ou federação? As montanhas e o Mediterrâneo parecem definir melhor as fronteiras da Itália que as dos sete Estados oitocentistas. O historiador inglês Dennis Mack Smith abre o seu livro sobre a Itália com esta constatação: "é pois com a geografia que deve começar a história italiana. [...] As montanhas não podem ser removidas, nem pela fé" 3 .

Mas deixemos esses exemplos para ver de que modo a tradicional relação entre direito e espaço se encontra hoje em crise, como consequência de dois fenômenos que estão colocando em crise o Estado nacional: a multiplicação de estruturas supranacionais e a globalização econômica.

\section{A GEOGRAFIA NO DIREITO PÚBLICO}

Antes de tudo, delimitemos as noções em uso da parte dos juristas recorrendo às clássicas enciclopédias jurídicas. No início do séc. XX, uma voz é dedicada à "Soberania" e outra ao "Território do Estado"; contudo, não se fala de "Espaço". Depois de 1950, dedicamse vozes ao "Território do Estado" e à "Soberania"; somente a afirmação da aeronáutica impõe introduzir a voz "Sobrevoo do território"; por fim, com a competição aeroespacial, surgem as vozes "Espaço aéreo" e "Espaço extraterrestre". Uma outra enciclopédia fala de "Território do Estado", de "Territorialidade" e de "Espaço aéreo". Para encontrar alguma voz geográfica, é preciso abandonar as enciclopédias jurídicas e passar às políticas; no Staatslexikon se encontram tanto Geographie como Geopolitik: conceito, este último, sobre o qual voltarei mais adiante, pois está carregado de história e de perigos.

Examinemos agora a relação clássica entre direito e geografia, limitando-nos aqui ao Direito público. O Direito administrativo, no interior de um particular Estado, determina as suas fronteiras internas entre regiões e províncias. Mas os políticos e os juristas não sentiram quase nunca a necessidade de escutar o parecer dos geógrafos. 
No Direito constitucional, a noção de território é essencial para definir um Estado, tanto em si como também com respeito aos outros Estados: juridicamente, não é concebível um Estado sem território (como não o seria sem população ou sem soberania; mas veremos que hoje essa construção jurídica apresenta algumas brechas). Ademais, a delimitação recíproca dos territórios estatais dá origem aos limites, às fronteiras, um dos conceitos fundamentais da geopolítica clássica.

No Direito internacional, esses limites ou fronteiras nacionais são objeto de tratados e de renegociações, sobretudo como consequência de uma guerra. As fronteiras podem ser modificadas por conquista (o Tratado de Versalhes, em 1919, modificava as fronteiras de quase toda a Europa centro-oriental) ou por aquisição. Por exemplo, os Estados Unidos adquiriram o Alaska dos russos no dia 30 de março de 1867 por 7,2 milhões de dólares. Os Estados Unidos conseguiram assim a exclusão da Rússia do continente americano; reforçaram a Doutrina Monroe ("América para os americanos"); e, ademais, com o prolongamento de sua própria soberania até as ilhas Aleutianas, os EUA criaram o fundamento para sua quase-supremacia marítima no Pacífico setentrional. Quase-supremacia que, num intervalo de tempo, tornou-se em supremacia de todo o Pacífico: e o Pacífico, faz uma década, substituiu ao Atlântico como área estratégico-econômica.

Antes de deixar estas considerações gerais sobre as relações entre direito e espaço geográfico, é necessário um alerta contra o nosso quase inevitável eurocentrismo.

A concepção europeia de espaço jurídico está vinculada às fronteiras nacionais, que circunscrevem a soberania do Estado. Desde essa nossa visão da soberania do Estado, derivam-se duas consequências.

A primeira consequência se refere ao fato de que a soberania do Estado nacional foi vista como a principal fonte das guerras. Contudo, depois das duas guerras mundiais na Europa, os Grandes impérios se fragmentaram em pequenos Estados: e isso aumentou a extensão das fronteiras e, portanto, as causas de conflito. Viu-se isso depois da queda dos Grandes impérios em 1919, com a fragmentação do Império Austro-húngaro e do Império Otomano; viu-se de novo depois da queda do Último império, ou seja, aquele Estado supranacional que foi a União Soviética, com a proliferação de Estados menores na área ex-soviética e, sobretudo, nos Bálcãs. O federalismo teórico, o Estado mundial, a "civitas maxima" - e, em concreto, a cinquentenária tentativa de federação europeia apresentam-se como remédios para a periculosidade das fronteiras nacionais.
A segunda consequência tem relação com o fato de que, em nossa visão ocidental, as pessoas que se encontram dentro de um certo Estado estão sujeitas ao direito interno desse Estado. Em outras palavras, o direito do Estado se aplica a quem se encontra no território desse Estado. Essa coincidência entre espaço geográfico e espaço jurídico parece óbvia para nós europeus; mas não é necessariamente assim.

A concepção islâmica do espaço jurídico está ligada à fé da pessoa, independentemente de sua pertença a um Estado nacional ou de sua presença no território deste. Todo crente islâmico está sujeito ao direito islâmico, onde quer que se encontre geograficamente; além disso, ao encontrar-se geograficamente dentro de um certo Estado, estará sujeito também ao direito desse Estado. Esse pluralismo jurídico gera situações jurídico-geográficas incompatíveis com nossa visão ocidental, mas normais num contexto islâmico.

Basta recordar o exemplo da condenação à morte de Salman Rushdie por seus "Versos satânicos". Um Aiatolá iraniano decreta uma fatwa que condena à morte um indiano, cidadão inglês, que vive na GrãBretanha, onde cometeu o delito/pecado de escrever um livro blasfemo. Essa condenação bate de frente contra todos os nossos princípios jurídicos ocidentais (baseados na concepção territorial do direito), mas é, por outro lado, uma consequência direta da concepção jurídica islâmica (baseada na concepção da sujeição pessoal ao direito). Rushdie, como islâmico, está sujeito ao direito islâmico independentemente do lugar em que se encontre: para o Ocidente, é uma situação aberrante, porque conduz ao conflito entre dois ordenamentos; para o Islã, é normal, porque o direito islâmico é de origem divina e, por conseguinte, superior a qualquer ordenamento humano.

As duas concepções jurídicas - a ocidental e a islâmica, a territorial e a pessoal - são inconciliáveis. Os mal-entendidos nascem do fato de que os europeus pensam o Estado, a soberania e as fronteiras segundo o seu modelo, enquanto que os islâmicos o fazem de acordo com o seu.

Entretanto, antes de rejeitar a concepção islâmica do direito, é necessário recordar que também no Ocidente estamos nos separando de uma concepção rigorosamente territorial do direito. Basta pensar na cada vez mais frequente presença de normas que atribuem jurisdição universal a um Estado particular. Um promotor público belga, por exemplo, pode abrir um procedimento contra uma pessoa que tenha violado os direitos humanos na Ásia ou na América do Sul. O problema é, pois, a aplicação desta norma individual: deve-se voltar ao princípio da presença do acusado no espaço geográfico do Estado de onde emana a denúncia. 
Isso não significa que os direitos ocidentais estão se islamizando; significa somente que os direitos ocidentais estão se afastando do princípio da rígida territorialidade na aplicação do direito. E é precisamente a esse tema que retorno após o excurso islâmico.

\section{ESPAÇO, ESPAÇO VITAL, "GRANDE ESPAÇO"}

O espaço geográfico é um elemento essencial para determinar o conceito de Estado. Contudo, enquanto que o espaço geográfico é estável - salvo nos grandes movimentos geológicos - o espaço estatal, ou seja, a sua fronteira, está em contínuo movimento, seja em vista de acordos pacíficos, seja por enfrentamentos bélicos com outros Estados. Ademais, ainda que as fronteiras físicas do Estado permaneçam invariáveis, é possível, entretanto, que mude o que o Estado pode fazer dentro de seus limites: com a introdução do Euro, por exemplo, os Estados da União Europeia já não podem exercitar a sua própria política monetária dentro dos limites nacionais; ou ainda, com os tratados de direito penal universal, o Estado nacional estende a sua jurisdição a todo o mundo.

Fiquemos agora na mutação das fronteiras nacionais. Pode-se fazer o registro das fronteiras tal como são agora: a geografia política descreve assim, por exemplo, os limites estatais da Europa. Mas um político pode desejar a expansão territorial do próprio Estado: seu projeto se apresentará então como uma política da geografia, como uma geopolítica, ou seja, como uma proposta de modificação de fronteiras por meio de pactos políticos ou, eventualmente, também com aquele prosseguimento da política por outros meios, que é a guerra. A geografia política é estática; a geopolítica é dinâmica. A geografia política descreve os limites como são; a geopolítica descreve os limites como deveriam ser.

Pode ocorrer que uma elite política, pelas mais variadas razões, não esteja satisfeita com suas próprias fronteiras nacionais. Então se mobilizará para modificálas de maneira pacífica ou violenta. Essa pressão para modificar (em vantagem própria) as fronteiras busca frequentemente valer-se de argumentos apresentados como científicos: e a ciência a que se apela é a geografia. Por isso, o geógrafo francês Yves Lacoste intitulou a um de seus livros de "A geografia, serve primeiro para fazer a guerra"4. Para mudar a geografia política de um continente, recorre-se assim a um uso político da geografia, a uma política da geografia, a uma geopolítica (cujo fim último é uma modificação também jurídica das fronteiras).

Entre o fim do séc. XIX e início do séc. XX, esta política da geografia foi organizada como ciência: a
Geopolítica. Nela, a concepção do espaço estatal vem a ser enriquecida com um perigoso conceito: o espaço se transformou em vital. Os acontecimentos das ditaduras europeias demonstraram que o uso político da teoria do espaço vital tem consequências mortais.

Inicialmente, a noção de espaço vital era científica e tinha a sua origem na fitogeografia e na zoogeografia. De fato, explicam os geógrafos e os biólogos, que todo ser vivo - planta, animal ou ser humano - tem necessidade de um mínimo de espaço que lhe permita sobreviver. Os problemas começam, porém, quando o "espaço vital" se une à concepção darwinista da "luta pela vida": o ser que se encontra num espaço não-vital deve conquistar o espaço vital ainda que seja com a luta, ou seja, com a violência ${ }^{5}$. Carl Schmitt teorizou exemplarmente essa concepção agressiva do espaço ${ }^{6}$. Se, pois, - como ocorreu na Alemanha nacional-socialista - ao espaço vital darwinisticamente entendido, acrescenta-se a concepção de que essa luta pela vida é conduzida em nome da afirmação de uma raça superior, chega-se às aberrações que caracterizaram as guerras de conquista em torno da metade do séc. XX.

Depois da Primeira Guerra Mundial, a originária concepção do "espaço vital" foi recebida por uma Alemanha dessangrada por causa das reparações bélicas, espoliada de seus territórios minerais e privada de suas colônias. As mutilações provocadas pelo Tratado de Versalhes lhe haviam retirado o "espaço vital" necessário para uma grande potência. E assim, a ciência do "espaço vital" se transformou numa geopolítica a serviço de uma política de expansão.

O drama vem porém com o advento do nacionalsocialismo ao poder, o qual decidiu reconquistar mediante a guerra o "espaço vital" que faltava a seu povo. Mas aqui entrou em jogo o elemento racial, ignorado pela geopolítica clássica: aquele povo em busca de seu espaço vital não era um povo qualquer: era um Herrenvolk, uma raça superior.

O passo sucessivo foi organizar o "espaço vital" conquistado em "Grandes Espaços", quase precursores (só que antidemocráticos) das formações supraestatais hodiernas. O grande espaço alemão compreendia também toda a URSS; aquele japonês se estendia até Cingapura; o italiano se dirigia à África. É inútil falar disso agora: o epílogo da teoria dos "Grandes Espaços" já foi escrito pela história.

\section{UMA CIÊNCIA ESQUECIDA: A GEOJURISPRUDÊNCIA}

A sorte da geopolítica no ambiente político, militar e acadêmico em que se movia Karl Haushofer induziu em 1928 o jovem jurista Manfred Langshans- 
Ratzeburg a elaborar uma "geojurisprudência", a saber, uma ciência que, para o direito, queria ser análoga a aquilo que a geopolítica era para a geografia ${ }^{7}$.

Seu manual de "geojurisprudência" foi publicado nos cadernos que acompanhavam a revista Geopolitik de Haushofer. Ali se constatava que já era o momento de pensar também na colaboração entre a geografia e o direito. A "geojurisprudência" que nasce desta fusão interdisciplinar é definida como "o ramo da ciência jurídica que busca explicar ou ilustrar os resultados da investigação jurídica mediante um tratamento geográfico e cartográfico" (p. 09). A cartografia se presta de modo especial a ilustrar "o âmbito de validade espacial dos fenômenos jurídicos" (p. 10).

Para Langhans, a geojurisprudência é uma disciplina auxiliar do direito e, como tal, faz parte do direito, já que é este último que deve determinar os seus objetivos. Se o ponto de partida da geojurisprudência é o direito, então é possível identificar algumas subseções desta em função das clássicas subdivisões do direito.

Em particular, o "Direito público geográfico" remete diretamente à geopolítica e a seus autores: aqui se cita antes de tudo aos pais da geopolítica, Ratzel e Kjellén, junto com os juspublicistas que haviam demonstrado maior abertura para os temas geográficos. Já Ratzel considerava que "para muitos juspublicistas, como também para muitos historiadores, o Estado está suspenso no ar"; para ele, entretanto, o Estado estava vinculado ao solo e esta sua concepção, continuada por Haushofer, suscitou críticas e promoveu novas investigações.

Entre as críticas, contam-se as da escola francesa e as da "pequena minoria guiada por Hans Kelsen", que considera o território como elemento físico irrelevante desde o ponto de vista jurídico; contudo, "a concepção do Estado que está na base de nossas asserções - precisa Langhans-Ratzeburg - situa-se no extremo oposto com respeito à da escola de Kelsen" (p. 26).

Em outros termos, mais que ao formalismo jurídico, a geojurisprudência preferia apelar ao jurista que sustentava que "precisamente em nossa época, os problemas da geografia política e da geopolítica são de grande importância para a doutrina do Estado": assim o sustentava Otto Koellreutter, destinado a converter-se em um dos juristas nacional-socialistas mais radicais. Também a geojurisprudência tem portanto relação com os juristas: e que juristas! Os "terríveis juristas" de Ingo Müller8.

A geojurisprudência teve uma sorte limitada nos anos das ditaduras europeias. Foi criticada também pelos juristas coevos. Por fim, terminou sendo esquecida por completo: e suponho que a evocação que faço hoje seja a primeira desde o final da Segunda Guerra Mundial.

\section{DO MATERIAL AO IMATERIAL: O GEO-DIREITO}

A afirmação da globalização está pondo em tela, entre os juristas, a concepção tradicional do espaço. Já se viu que o espaço foi considerado como o suporte físico do ordenamento jurídico: de fato, o limite espacial do Estado (a fronteira) assinalava também o limite da eficácia de seu ordenamento jurídico. Até que ponto pode adaptar-se esta doutrina jurídica tradicional ao mundo hodierno, em cujos limites espaciais não são mais rigidamente circunscritos?

Uma resposta a essa pergunta sobre a relação entre direito e espaço foi proposta em 2001 num ensaio de Natalino Irti, que aqui não é possível analisar ${ }^{9}$ : nele se examinavam as relações entre direito, economia e política, afrontando neste contexto também o problema dos direitos humanos.

A noção de "geo-direito" não vem explicitamente definida, mas se extrai do contexto que delineia as relações entre o espaço e o direito. O prefixo "geo" indica o espaço em que se estende a atividade estatal ou econômica (mas não o ambiente), enquanto que o "direito" - em singular - é entendido na sua totalidade, isto é, como ordenamento jurídico. Radical é portanto a diferença do geo-direito de Irti com respeito à geojurisprudência de Langhans: esta última se apresenta como uma ciência auxiliar de um direito positivo em particular ou de grupos de direitos positivos, enquanto que o "geo-direito" de Irti se apresenta como uma teoria geral do direito (entendido este último como ordenamento jurídico global).

Dos "grandes espaços" de Schmitt se passa assim aos "novos espaços" determinados pela globalização (e, portanto, pela "desterritorialização") da economia.

Os dois autores até aqui examinados ilustraram as relações entre espaço e direito desde específicos pontos de vista: a geojurisprudência de Langhans está vinculada aos conceitos nacional-socialistas de espaço vital e de Grandes Espaços; o geo-direito de Natalino Irti está vinculado aos conceitos neoliberais da globalização, sobretudo a econômica.

Agora é necessário passar destes dois autores exemplares a considerações mais gerais. Estas últimas devem reduzir-se a alguns acenos, porque o debate sobre o direito, o espaço e a globalização já está ocupando uma biblioteca inteira.

\section{EM BUSCA DO ESPAÇO PERDIDO}

Na segunda metade do séc. XX, a geopolítica e a geojurisprudência, como seu ramo menor, foram excluídas do debate científico por duas razões. De 
um lado, a geopolítica era vista como a justificação ideológica das guerras de agressão nazi-fascistas, e era percebida, portanto, como uma disciplina ideologicamente comprometida. De outro lado, com o fim da Segunda Guerra Mundial, as fronteiras territoriais (melhor dito, "geopolíticas" em seu sentido neutral original) haviam sido substituídas pelas fronteiras ideológicas entre liberalismo e comunismo.

Hoje, a redescoberta do espaço geográfico está conectada ao fim daquele mundo bipolar e à globalização econômica: e, visto que o direito é influenciado pela economia, e este, por sua vez, plasma a economia, no debate jurídico, o espaço volta ao primeiro plano e em termos novos.

Dito brevemente: o fim da dicotomia ideológica entre liberalismo e comunismo, próprio da Guerra Fria, e o início da globalização econômica, própria do neoliberalismo, levaram os juristas a constatar que o espaço do direito de hoje já não é mais o espaço do direito de um século atrás.

Os mapas geojurídicos voltaram a ser utilizados. Em 1992, veio à luz um Atlas de direito privado comparado editado por Francesco Galgano. Estão se multiplicando os atlas históricos que apresentam também muitos mapas geo-históricos: e não esqueçamos que Jaime Vicens Vives havia rebatizado como "geo-história" aquela "geopolítica" que tinha praticado até 1950. Desde os anos noventa, multiplicam-se os estudos com o prefixo "geo-" em âmbitos até então raros: os filósofos Massimo Cacciari e Gilles Deleuze afrontam a "geofilosofia". Esboça-se não só uma geofilosofia do direito, senão também uma geofilosofia do mar e uma da paisagem. Em 2009, a revista Limes publicando um número dedicado ao Vaticano como potência mundial, inaugurou, de fato, uma geoteologia ou uma teopolítica.

Entretanto, entre os estudiosos, são, sobretudo, os juristas aqueles que parecem andar em busca do espaço perdido, porque a globalização fez saltar as fronteiras nacionais, as quais, para os juristas, constituíam um limite, mas também uma certeza. Nos novos livros circulam fórmulas aterradoras para um jurista tradicional. $\mathrm{O}$ direito se apresenta agora como um direito global, mas sem Estado: "Direito global sem Estado" é como se intitula um livro de Teubner. O grande volume alemão, "Espaço e Direito", redefine a noção de espaço em quase todos os setores jurídicos. Outros autores falam de "direito sem fronteiras", de "espaço jurídico global", de "retirada do Estado", e assim sucessivamente até as "leges proter legem", formulação que leva à desesperação qualquer juspositivista ortodoxo.
O elenco dos juristas em busca do espaço perdido aumenta dia a dia. Pode-se tentar traçar uma história desta recherche $e^{10}$ - desde os temas teóricos mais gerais até aqueles jurídicos mais específicos partindo da diferença entre o liberalismo de Hayek e o neoliberalismo da Escola de Chicago, para aprofundar depois a relação entre democracia e direito na pósmodernidade, tal como aparece na polêmica jurídicopolítica entre os herdeiros da Escola de Frankfurt, Franz von Neumann e Jürgen Habermas. Enfim, no âmbito mais estritamente jurídico, engrossam-se os escritos em que os especialistas de particulares setores do direito positivo se interrogam sobre as novas regras que a mundialização introduziu em cada setor jurídico.

Entre as inumeráveis contribuições recentes, recordo somente que, em 2004, no congresso da IVR ${ }^{11}$ em Granada, não poucos juristas voltaram ao tema; tanto foi assim que suas contribuições foram compiladas depois num único volume. $\mathrm{E}$ cada um dos textos citados reenviava a uma bibliografia tão copiosa como pertinente.

Ante essa imponente massa bibliográfica, limitarme-ei a indicar os temas que atualmente me parecem mais cruciais ${ }^{12}$.

\section{A DILATAÇÃO DO ESPAÇO: DO ESPAÇO TERRESTRE AO ESPAÇO CELESTE}

O espaço estatal - o antigo "território do Estado" está hoje superado, não somente pelas regras de origem não-estatal (o assim chamado soft law, entendido no sentido mais lato), senão também pelas exigências geopolíticas de natureza energética ou militar.

A geopolítica do petróleo está redesenhando novas alianças e novos conflitos territoriais: nestes, os discursos do poder ideológico ou político se entrecruzam com as pressões e as regras das companhias petrolíferas. A previsível insuficiência de alimentos está levando a China a adquirir terras na África. A crise da água conduz a tensões entre Estados nacionais quando um destes constrói diques sobre rios, bloqueando assim a água para outros Estados; mas, ao mesmo tempo, os lobbies e o soft law das multinacionais de bebidas estão empurrando em direção a uma privatização da água: um bem do mercado seguro e inexaurível. Todas estas pressões visam restringir sempre mais o âmbito do direito de origem estatal: e se considera "direito" também o direito produzido por órgãos supraestatais, mas democráticos, isto é, nascidos de eleições democráticas.

As relações entre direito nacional e regras supraestatais se estão fazendo sempre mais fluidas ou assimétricas: considere-se, por exemplo, a partição da 
Antártida e o uso do espaço extraterrestre. A Antártida está, de fato, subdividida em esferas de influência de vários Estados, enquanto que, desde 1959, o Tratado da Antártida a declara patrimônio da humanidade e, por isso, subtraída das soberanias nacionais; sete destas, contudo, mantêm pretensões territoriais sobre alguma de suas porções. O espaço extraterrestre é desde faz tempo objeto de uma "astropolítica" e de uma regulamentação jurídica, porque já se converteu numa área de exploração econômica e de interesse militar.

Em suma, a política de cada Estado já se projeta para além das próprias fronteiras nacionais, ao menos na mesma medida em que se desempenha no interior destas. Abre-se assim o dilema de se estas atividades fora do espaço estatal devem abandonar-se às regras das entidades supraestatais (empresas multinacionais, organismos vários), ou se também a política do Estado, mais além do próprio território, deve fundar-se em normas jurídicas tradicionais - por exemplo, de direito internacional público - para não gerar tensões e não degenerar em conflitos militares.

\section{UM RETORNO AO DIREITO ESTATAL PARA EVITAR NOVAS CATÁSTROFES?}

A concepção dominante entre os juristas reconhece como "direito" positivo somente as normas que são produzidas pelo órgão estatal delegado para tanto, ou quando muito as regras externas a este ordenamento, contanto que explicitamente demandadas por este: por exemplo, os usos comerciais. Fora deste âmbito, não se fala de direito (em sentido técnico), mas sim de regras, costumes, estatutos internos de empresas ou de organizações internacionais ou não governamentais, e assim por diante. Entretanto, para o jurista, só o direito positivo pode definir-se como direito: para ele, a pedra de toque - o "shibboleth"13 - é a "justiciabilidade" de uma norma, ou seja, o fato de que o cidadão possa pretender que um tribunal lhe reconheça um direito seu fundado nesta norma.

$\mathrm{O}$ tradicional direito estatal (estruturado hierarquicamente desde a Constituição até a sentença) se apresenta como insuficiente. De fato, como constatava Teubner em 1997, "a globalização rompe este marco"14, porque a economia globalizada "está pressionando para um direito global que não tenha legislação" 15 , isto é, que impõe abandonar o modelo hierárquico (a pirâmide normativa kelseniana) por uma norma "heterárquica" 16 , nascida, pois, na sociedade, "na periferia do sistema jurídico" 17 , num processo de "produção de regras por governos privados"18,19: frase decididamente alarmante não somente para os juristas, senão também para os defensores da democracia.
$\mathrm{Na}$ esteira desta concepção, a lex mercatoria infringe "o insuportável monopólio do Estado na criação do direito"20; toda empresa supranacional produz regras que são internas para a empresa, mas que transcendem as fronteiras nacionais; por conseguinte, "cada empresa constitui um ordenamento jurídico"21: "O Estado aparece, com efeito, como uma instituição subsidiária; o primeiro que surge no ordenamento jurídico positivo do Estado liberal são os direitos de propriedade e a liberdade contratual"22,23. Neste ponto, aquele que tem a propriedade é que estabelece o assim chamado "direito" extraestatal. Seria necessário, em definitivo, aceitar um sistema pluralista de normas, em que um dos subsistemas seria o direito positivo estatal. Um deles, repito. E sequer é o mais importante.

Análises análogas têm por objeto os processos que, por sua própria natureza, não tomam em consideração as fronteiras nacionais: o controle do clima, a difusão das telecomunicações, os perigos da energia atômica, a gestão da Internet, os casos de insolvência internacional, as novas relações de trabalho no mundo globalizado, a globalização dos direitos humanos, etc. E aqui convém deter-se para tirar as contas, considerando o mundo em que vivemos e viveremos nos próximos anos, e não o mundo de um futuro afastado.

Para resumir de forma muito sintética. Nas últimas décadas, assistimos a uma euforia de fusões entre empresas, porque as grandes dimensões foram consideradas mais adequadas para o mercado globalizado: no mercado mundial, tinha que operar uma empresa também mundial, ou seja, multinacional.

As empresas globais alcançaram dimensões que o Estado nacional singular já não é capaz de controlar, também porque sua legislação se detém nos limites nacionais. Essa fronteira, contudo, não existe para a empresa multinacional. A empresa multinacional se move assim num espaço juridicamente escasso e providencia por si mesma emanar regras de comportamento, não só para ela mesma, mas também para os outros. E aqui surgem as dúvidas: quem determina o conteúdo destas regras? Se há um procedimento para produzi-las, quem garante que seja seguido corretamente? Quem determina que instância seja competente para julgar os eventuais conflitos? O quesito, pois, se tudo isso é democrático nem sequer vem formulado: a empresa é, por sua própria natureza, autocrática.

Entretanto, esse gigantismo é um déjà vu histórico, seja com todas as cautelas que exigem as comparações entre épocas diversas. Os grandes monopólios da Itália fascista, os Konzerne da Alemanha nacional-socialista e os Zaibatsu do Japão militarista proporcionaram a infraestrutura para a gestão industrial dos "Grandes 
Espaços" imperiais, dos quais já falamos. Aqueles "Grandes Espaços" foram o sustento econômico e bélico das ditaduras até o ponto em que uma das primeiras medidas dos aliados vitoriosos consistiu em desmembrá-los em unidades menores, controláveis, assim, da parte do Estado nacional.

Hoje, afirma-se, a situação é distinta. Os Estados não são ditatoriais, mas democráticos. As multinacionais se outorgam códigos éticos de conduta. As palavras são formosas, mas os fatos não o são tanto. As empresas multinacionais influem em Estados nacionais através das manobras dos "lobbies" e do financiamento dos partidos (ou diretamente dos políticos). Por isso, também na administração pública se fala cada vez menos de governo (um dos três poderes de Estado) e cada vez mais de governança ${ }^{24}$ (entidade menos estruturada que um ectoplasma). Quanto aos códigos éticos de conduta, a empresa que os produz não é só a que os aplica, senão que também é quem julga a respeito de sua correta aplicação. Posto que a empresa multinacional não conhece a divisão de poderes própria do Estado nacional, esses códigos éticos podem definir-se com razão - é o título de um ensaio - como uma "folha de parreira" 25,26 .

Por detrás do movimento da "desregulamentação" 27 - ou seja, da dissolução dos vínculos do Estado em razão do livre desenvolvimento da economia - estão as teorias econômicas do neoliberalismo (assim como nas ditaduras europeias se encontrava a doutrina econômica do corporativismo); não de outra maneira, as teorias neoliberais foram traduzidas em medidas políticas por George Bush senior e por Margaret Thatcher (mas aqui me detenho com os paralelismos, porque seriam não somente pouco generosos, senão também falsos). Porém, não são esquecidas as novas ideologias subjacentes aos fatos econômicos e jurídicos hodiernos.

Ainda hoje, a economia segue vivendo sob o lema de "menos Estado e mais mercado". A progressiva diminuição dos controles públicos sobre a economia privada conduziu provavelmente à maior crise econômica do séc. XX: esperemos os dados definitivos para saber se a presente é maior que a de 1929.

Neste ponto o vituperado Estado foi convidado a intervir com somas gigantescas para sanar as perdas produzidas pelo mítico mercado. Onde estava a "mão invisível" que deveria tê-lo regulado? Em realidade, aquela mão é invisível porque simplesmente não existe.

Assim, depois de ter assistido até os anos 80-90 a uma gigantesca transferência de riqueza desde as rendas baixas às altas, resulta que hoje essas mesmas rendas baixas estão chamadas a sanar com seus impostos as dívidas devidas à torpeza e avidez das grandes multinacionais. Estas últimas, agora, guardamse bem antes de pedir "menos Estado e mais mercado"; em troca, o castigo mais apropriado, ainda que muito cruel, seria precisamente a aplicação do capitalismo aos próprios capitalistas: a falência.

Mas em seguida surge a chantagem: o desemprego produzido pela falência de uma grande multinacional criaria, para o Estado nacional, um problema não só econômico, mas, sobretudo, social. E os desempregados votam. Assim, as classes de renda baixa - que já foram empobrecidas nos decênios passados e que agora pagam as dívidas das multinacionais com a redução dos serviços sociais e com seus impostos e os de seus filhos - servem também como álibi para uma nova e gigantesca privatização do dinheiro público.

$\mathrm{E}$, ao final, este custoso salvamento público não garante nada contra a repetição de um desastre análogo: pelo contrário, a julgar pelo que ocorre no mundo financeiro, parece que tudo vai voltar a ser como antes da derrubada, e assim à espera da próxima. O problema é, pois, como sair de uma estrutura globalizada que está dando uma péssima imagem de si mesma, mas que pretende ditar por si mesma as regras para autogestionar-se: o tão elogiado soft law.

Um primeiro dado de fato de onde partir é que já não se pode mais voltar para atrás: a globalização é um fato irreversível. Irreversível mas dominável: o que ocorre é que até agora se fez pouco ou nada para dominálo, porque a política era (e segue sendo) condicionada por demasiados interesses associados à economia globalizada. Se a crise não parece ter galvanizado os políticos, é esperável que sejam os cidadãos os que vão galvanizá-los com seu voto. A política talvez devesse reduzir as dimensões das empresas multinacionais que já operam em regime de oligopólio ou de monopólio, assim como sucedeu com os Konzerne e os Zaibatsu no final da Guerra. Mas, sobretudo, é necessário introduzir eficazes controles nacionais e supranacionais.

Estes controles deverão ser democráticos, isto é, deverão passar através de uma legislação aprovada por parlamentos nacionais ou supranacionais, mas em todo caso eleitos. O direito "piramidal" ou hierárquico voltaria a exercitar sua função reguladora, estando controlado e equilibrado mediante a divisão de poderes. Uma vez que a globalização é um fato irreversível, seria ilusório tentar eliminar o arsenal de regras, disposições e autorregulamentações que caem sob a rubrica de soft law: mas o Estado individual ou uma organização supraestatal deverão dispor de instrumentos para controlá-los. E a história demonstra que isso é possível.

Se se quer o controle da globalização, no âmbito do direito deverá repetir-se o que ocorreu faz séculos no direito comercial. A corporação medieval europeia 
regulava os usos comerciais e julgava as controvérsias que nasciam entre os mercadores. Daquela prática nasceu um direito comercial que se cristalizou em códigos de comércio, absorvidos depois nos códigos civis. Inclusive o rígido direito islâmico se adequou às exigências do comércio: aceitou a "comenda", um negócio que, em rigor, implicava um risco proibido pelo Alcorão, ou outros negócios teologicamente duvidosos. Contudo, não os aceitou de maneira informal: foi preciso que os experts em direito religioso - os "ulemas" - declarassem legítimo um negócio "porque foi usado constantemente nas relações" e "porque as pessoas têm necessidade dele". Porque, então, a atual lex mercatoria do mundo global, que remete ao passado até em seu nome latino, não poderia percorrer o mesmo caminho e ser gradualmente recebida num hard law ${ }^{28}$ ?

Se não se encontra uma via para controlar a globalização - a que foi mencionada antes é só uma das possibilidades - corre-se o risco de recair numa nova crise globalizada. É inútil pedir previsões aos experts: deve-se aceitar o fato de que também a imprevisibilidade forma parte do destino humano.

O verdadeiro risco é que no mundo estão se acumulando problemas não só econômicos: a crise do meio ambiente provocará instabilidade social; a proliferação atômica gerida por governos não confiáveis criará problemas de segurança internacional; a exportação de modelos políticos (tanto democráticos como teocráticos) gerará conflitos militares; as crises alimentares causarão migrações e reações violentas. Se mais de uma destas crises potenciais se realizará em concomitância com uma nova queda econômica, o colapso será universal, assim como universal é o mundo criado por nós.

Até agora a sociedade mundial resistiu bastante bem a colapsos setoriais: mas alguns deles levaram à desaparição de civilizações inteiras. Se não se quer que Terra inteira termine como a civilização dos maias, dos vikings ou de outras culturas desaparecidas, como descreve Jared Diamond ${ }^{29}$, é necessário controlar a globalização. E uma parte da solução pode consistir no retorno a formas de direito rígido, de law mas nada soft.

Sem um controle global, também a queda será global. Tão global que - se é que chega - nem sequer terei a satisfação de poder dizer: "Eu já havia dito isso!”.

\section{REFERÊNCIAS}

CUTLER, Claire. Globalization, the Rule of Law, and the Modern Law Merchant: Medieval or Late Capitalist Associations? Constellations, 2001.

DIAMOND, Jared. Collaps: How Societies Choose to Fail or to Succeed. New York: Viking Press, 2005.

FRITSCH-OPPERMANN, Sybille; OPPERMANN, Berndt H. Verhaltenskodex für Multinationale Konzerne: Feigeblatt der Globalisierung? In: NAHAMOWITZ, Peter; VOIGT, Rüdiger (Hrsg.). Globalisierung des Rechts II: Internationale Organisationen und Regelungsbereiche. Baden-Baden: Nomos-Verlag, 2002.

IRTI, Natalino. Norma e luoghi: Problemi di geo-diritto, Roma/ Bari: Laterza, 2006.

LANGHANS-RATZEBURG, Manfred. Begriff und Aufgaben der geographischen Rechtswissenschaft (Geojurisprudenz): Systematisches über die Beziehungen der Rechtswissenschaft zur Geographie, Kartographie und Geopolitik. Berlin: Vowinckel Verlag, 1928.

LANGHANS-RATZEBURG, Manfred. Geopolitik und Geojurisprudenz. Jena: Fromann, 1932.

LOSANO, Mario G. La geopolitica nazionalsocialista e il diritto internazionale dei "grandi spazi". Materiali per una storia della cultura giuridica, XXXV, 2005, n. 1, p. 05-63.

MERTENS, Hans-Joachim. Lex mercatoria: A Self-applying System Beyond National Law? In: TEUBNER, Gunther. Global Law without a State, Aldershot, GB: Dartmouth, 1997.

MÜLLER, Ingo. Furchtbare Juristen: Die unbewältigte Vergangenheit unserer Justiz. München: Kindler, 1987.

SCHMITT, Carl. Die Raumrevolution. Das Reich, 29 de setembro de 1940.

SCHMITT, Carl. Reich und Raum: Elemente eines neuen Völkerrechts. Zeitschrift der Akademie für Deutsches Recht, 1941.

SCHMITT, Carl. Völkerrechtliche Grossraumordnung mit Interventionsverbot für raumfremde Mächte: Ein Beitrag zum Reichsbegriff im Völkerrecht. Berlin: Deutscher Rechtsverlag, 1939.

SMITH, Dennis Mack. Italy: A Modern History. Ann Arbor/ Michigan, USA: University of Michigan Press, 1959, p. 01 e ss.

TEUBNER, Gunther (ed.). Global Law without a State. Aldershot, GB: Dartmouth, 1997.

\section{NOTAS}

1 Texto original em italiano: LOSANO, Mario G. Diritto e geografia: lo spazio del diritto e il mondo della geografia. Legal Roots: The International Journal of Roman Law, Legal History and Comparative Law, 2012, n. 1, p. 05-21. Versão em espanhol, impressa: LOSANO, Mario G. Derecho y geografía: El espacio del derecho y el mundo de la geografía. Discurso de investidura como Doctor Honoris Causa por la Universidad Carlos III de Madrid. In: Autonomía universitaria y libertad académica, Servicio de Relaciones Institucionales y Protocolo de la Universidad Carlos III de Madrid, Boletín Oficial del Estado, Madrid,
2010, p. 391-408. Versão eletrônica: LOSANO, Mario G. Derecho y geografía - El espacio del derecho y el mundo de la geografia. Disponível em: <http://e-archivo.uc3m.es/bitstream/10016/10322/1/Discurso\%20 de\%20Mario\%20G.\%20Losano.pdf>. Agradece-se ao editor da revista Legal Roots, Salvatore Randazzo, pela autorização para publicação em língua portuguesa.

2 Professor emérito de Filosofia do Direito e de Introdução à Informática jurídica na Faculdade de Direito da Università del Piemonte Orientale "Amedeo Avogadro" (Alessandria). Professor no Curso de Doutorado em Direito e Instituições da Università degli Studi di Torino. Prêmio Alexander von Humboldt-Forschungspreis, 1995, Bonn, Alemanha. 
Doutorados honoris causa pela Gottfried Wilhelm Leibniz Universität Hannover (Alemanha, 2004), Universidad de la República (Montevidéu, Uruguai, 2008), Universidad Carlos III (Madrid, Espanha, 2009). O autor possui inúmeras publicações em livros, artigos científicos e capítulos de livros. Tem textos traduzidos para 12 línguas. Informações: $<$ http://www. mariolosano.it/>. E-mail: <mario_losano@yahoo.it>.

3 SMITH, Dennis Mack. Italy: A Modern History. Ann Arbor/Michigan, USA: University of Michigan Press, 1959. p. 01. No original italiano do texto, a citação está em inglês: "Its is therefore with geography that Italian history must begin. [...] Mountains may not be removed, even by faith".

4 Nota de tradução: a expressão aparece em francês no original italiano do texto. Trata-se do livro: LACOSTE, Yves. La géographie, ça sert d'abord à faire la guerre. Paris: Maspero, 1976.

5 Para uma análise mais detalhada destes conceitos - LOSANO, Mario G. La geopolitica del Novecento: dai Grandi Spazi delle dittature alla decolonizzazione. Milano: Bruno Mondadori, 2011.

6 SCHMITT, Carl. Die Raumrevolution. Das Reich, 29 de setembro de 1940, p. 03; SCHMITT, Carl. Reich und Raum: Elemente eines neuen Völkerrechts. Zeitschrift der Akademie für Deutsches Recht, 1941, p. 145-149; SCHMITT, Carl. Völkerrechtliche Grossraumordnung mit Interventionsverbot für raumfremde Mächte: Ein Beitrag zum Reichsbegriff im Völkerrecht. Berlin: Deutscher Rechtsverlag, 1939; cfr. LOSANO, Mario G. La geopolitica nazionalsocialista e il diritto internazionale dei "grandi spazi". Materiali per una storia della cultura giuridica, XXXV, 2005, n. 1, p. 05-63.

7 LANGHANS-RATZEBURG, Manfred. Begriff und Aufgaben der geographischen Rechtswissenschaft (Geojurisprudenz): Systematisches über die Beziehungen der Rechtswissenschaft zur Geographie, Kartographie und Geopolitik. Berlin: Vowinckel Verlag, 1928. No texto, as páginas indicadas entre parênteses se referem a esta publicação. Cfr. LANGHANS-RATZEBURG, Manfred. Geopolitik und Geojurisprudenz. Jena: Fromann, 1932

8 MÜLLER, Ingo. Furchtbare Juristen: Die unbewältigte Vergangenheit unserer Justiz. München: Kindler, 1987.

9 IRTI, Natalino. Norma e luoghi: Problemi di geo-diritto, Roma/Bari: Laterza, 2006. A primeira edição de 2001 foi publicada no mesmo ano de seu artigo - IRTI, Natalino. Geo-diritto. Rivista Italiana di Filosofia del Diritto, 2001, p. 461-468.

${ }_{10}$ Nota de tradução: na versão original do texto, o autor utilizou a expressão em francês, que significa "pesquisa".

${ }^{11}$ Nota de tradução: trata-se da "Associação Internacional de Filosofia do Direito" ("Internationale Vereinigung für Rechts- und Sozialphilosophie").

12 Nota de tradução: frase presente somente na versão espanhola do texto, lida na cerimônia do Doutorado honoris causa mencionada anteriormente.
${ }^{13}$ Nota de tradução: expressão de origem hebraica utilizada no original italiano do texto, no sentido de "senha" - existe a forma "xibolete" na língua portuguesa.

${ }^{14}$ Nota de tradução: no original italiano do texto, a expressão está em inglês: "globalization breaks this frame".

15 Nota de tradução: no original italiano do texto, a expressão está em inglês: "is pressing for a global law that has no legislation".

16 Nota de tradução: no original italiano do texto, a expressão está em inglês: "heterarchical".

${ }^{17}$ Nota de tradução: no original italiano do texto, a expressão está em inglês: "in the periphery of the legal system".

18 TEUBNER, Gunther (ed.). Global Law without a State. Aldershot, GB: Dartmouth, 1997. p. XIII-XV.

19 Nota de tradução: no original italiano do texto, a expressão está em inglês: "rule-making by private governments".

${ }^{20}$ Nota de tradução: no original italiano do texto, a expressão está em inglês: "the unbearable monopoly of State law creation".

${ }^{21}$ Nota de tradução: no original italiano do texto, a expressão está em inglês: "each enterprise constitutes a legal order".

${ }^{22}$ MERTENS, Hans-Joachim. Lex mercatoria: A Self-applying System Beyond National Law? In: TEUBNER, Gunther. Global Law without a State, cit., p. 57.

${ }^{23}$ Nota de tradução: no original italiano do texto, a expressão está em inglês: "The state effectively appears as a subsidiary institution: what comes first in the positive legal order of the liberal state are property rights and liberty of contract".

${ }^{24}$ Nota de tradução: no original italiano do texto, a expressão está em inglês: "governance", que traduzimos como "governança" ao português.

25 FRITSCH-OPPERMANN, Sybille; OPPERMANN, Berndt H. Verhaltenskodex für Multinationale Konzerne: Feigeblatt der Globalisierung? In: NAHAMOWITZ, Peter; VOIGT, Rüdiger (Hrsg.). Globalisierung des Rechts II: Internationale Organisationen und Regelungsbereiche. Baden-Baden: Nomos-Verlag, 2002. p. 357-380.

${ }^{26}$ Nota de tradução: a expressão "folha de parreira" (que pode ser com outras folhas, como a da figueira comum) faz alusão à narrativa do Gênesis bíblico sobre o pudor de Adão e Eva.

${ }^{27}$ Nota de tradução: no original italiano do texto, a expressão está em inglês: "deregulation", que traduzimos como "desregulamentação" ao português.

${ }^{28}$ CUTLER, Claire. Globalization, the Rule of Law, and the Modern Law Merchant: Medieval or Late Capitalist Associations?. Constellations, 2001, p. 480-502.

29 DIAMOND, Jared. Collaps: How Societies Choose to Fail or to Succeed. New York: Viking Press, 2005. p. 592. 